\title{
Local genetic ancestry in CDKN2B-AS1 is associated with primary open-angle glaucoma in an African American cohort extracted from de-identified electronic health records
}

\author{
Nicole A. Restrepo ${ }^{1}$, Sarah M. Laper ${ }^{2}$,Eric Farber-Eger ${ }^{3}$ and Dana C. Crawford ${ }^{1 *}$
}

From The 7th Translational Bioinformatics Conference

Los Angeles, CA, USA. 29 September - 01 October 2017

\begin{abstract}
Background: Glaucoma is a leading cause of blindness in developed countries. Primary open-angle glaucoma (POAG), the most prevalent clinical subtype of glaucoma in the United States, affects African Americans at a higher rate compared with European Americans. Risk factors identified for POAG include increased age and family history, which coupled with heritability estimates, suggest this complex condition is associated with genetic and environmental factors. To date, several genome-wide studies have identified loci significantly associated with POAG risk, but most of these studies were performed in populations of European-descent.

Methods: To identify population-specific and trans-population genetic associations for POAG, we genotyped 11,521 African Americans using the Illumina Metabochip as part of the Epidemiologic Architecture for Genes Linked to Environment (EAGLE) study accessing BioVU, the Vanderbilt University Medical Center's biorepository linked to deidentified electronic health records. Among this study population, we identified 138 cases of POAG and 1376 controls and performed Metabochip-wide tests of association. We also estimated local genetic ancestry at CDKN2B-AS1, a POAG-associated locus established in European-descent populations.
\end{abstract}

Results: Overall, we did not identify significant single SNP-POAG associations after adjusting for multiple testing. We did, however, detect a significant association between POAG risk and local African genetic ancestry at CDKN2B-AS1, where on average cases were of 90\% African descent compared with controls at 58\% $\left(p=2 \times 10^{-6}\right)$.

Conclusions: These data suggest that CDKN2B-AS1 is an important locus for POAG risk among African Americans, warranting further investigation to identify the variants underlying this association.

Keywords: African Americans, Primary open-angle glaucoma, Electronic health records

\footnotetext{
* Correspondence: dana.crawford@case.edu

${ }^{1}$ Department of Population and Quantitative Health Sciences, Institute for Computational Biology, Case Western Reserve University, 2103 Cornell Road, Wolstein Research Building, Suite 2-527, Cleveland, OH 44106, USA Full list of author information is available at the end of the article
}

(c) The Author(s). 2018 Open Access This article is distributed under the terms of the Creative Commons Attribution 4.0 International License (http://creativecommons.org/licenses/by/4.0/), which permits unrestricted use, distribution, and reproduction in any medium, provided you give appropriate credit to the original author(s) and the source, provide a link to the Creative Commons license, and indicate if changes were made. The Creative Commons Public Domain Dedication waiver (http://creativecommons.org/publicdomain/zero/1.0/) applies to the data made available in this article, unless otherwise stated. 


\section{Background}

Glaucoma is the second leading cause of blindness in the United States, and it is the leading cause of blindness and irreversible vision loss in African Americans [1], with a prevalence approximately double that observed in European-descent populations [1-3]. The prevalence of glaucoma is similar for European, Japanese, and Indian populations with rates approaching those observed in African descent populations in the oldest age categories [4]. Although African Americans comprise the group of highest risk of developing glaucoma-related vision problems, many cases remain undiagnosed. Previous studies have suggested that nation-wide implementation of screening middle aged African Americans could decrease the rate of undiagnosed glaucoma from 50 to 27\% [5]. Earlier screening and diagnosis enables patients to more effectively leverage current treatment options to reduce the risk of bilateral blindness later in life [5].

In addition to African ancestry and age [6], other known risk factors associated with the development of glaucoma include myopia [7] and high intraocular pressure [6, 8, 9]. Family history has also been associated with glaucoma risk $[6,10,11]$, albeit inconsistently most likely due to the heterogeneous nature of the disease. The phenotypic heterogeneity of glaucoma has also impacted other studies attempting to establish and quantify the genetic contribution to risk in developing the disease; consequently, the majority of these studies have been conducted on more easily-measured glaucoma endophenotypes such as central corneal thickness $\left(\mathrm{h}^{2}=0.35-0.72 \%\right)[12-14]$, intraocular pressure $\left(\mathrm{h}^{2}=0.35-0.94 \%\right)[12,14]$, and cup-to-disc ratio $\left(\mathrm{h}^{2}=0.56-0.66 \%\right)[12,15]$. Pulsatility of choroidal blood flow and velocity are additional quantitative traits whose variation from normal parameters has been observed in individuals with glaucoma $[16,17]$, yet heritability studies have not yet found significant genetic contribution to its variability [12].

The strongest evidence for a genetic contribution related to glaucoma comes from studies of primary open-angle glaucoma (POAG), the most prevalent clinical subtype of glaucoma in the United States. Early linkage and family-based genetic association studies identified the MYOC (myocilin), OPTN (optineurin), and WDR36 (WD repeat domain 36) [18-20] genes as the primary genes for susceptibility to POAG. Mutations in MYOC are known to cause hereditary early-onset POAG in multiple populations [18, 21, 22]. More recently, large-scale genome-wide association studies (GWAS) have identified variants in the $C A V 1 / C A V 2, C D K N 2 B-A S 1$ and SIX1/SIX6I genes that influence POAG risk in European-descent and Japanese populations [23-27].

Additional genetic factors that have yet to be discovered are hypothesized to drive POAG risk and to account for the differences in incidence observed across racial/ethnic groups. For example, in a study of African Americans, the frequency of $M Y O C$ mutations was comparably lower $(\sim 1.4 \%)$ than in other populations $(\sim 2-4 \%)$ [28] suggesting that other genetic loci are driving risk in this group. It is possible that both population-specific and trans-population genetic variants contribute to POAG risk. To identify population-specific and trans-population genetic factors, we conducted a hypothesis-testing and hypothesis-generating genetic association study in African Americans with and without POAG drawn from a clinical cohort with electronic health records.

\section{Methods}

\section{Study population and genotyping}

The study population is a subset of the Epidemiologic Architecture for Genes Linked to Environment (EAGLE) study, a study site of the larger Population Architecture using Genomics and Epidemiology (PAGE) I study [29, 30]. In general, the PAGE study is a consortium of diverse epidemiologic and clinical cohorts with broad research goals that include the generalization of genetic associations to multiple populations [29]. To identify non-European Americans for PAGE I, EAGLE accessed the Vanderbilt University Medical Center (VUMC)'s biorepository linked to de-identified electronic health records known as BioVU [31].

VUMC's BioVU followed an opt-out model for DNA sample accrual between 2007 and 2015 [31]. That is, DNA was collected from discarded blood samples remaining after routine clinical testing and was linked to de-identified electronic health records. According to the Vanderbilt Institutional Review Board (IRB) and the Federal Office of Human Research Protections provisions, this VUMC protocol is considered nonhuman subjects research (The Code of Federal Regulations, 45 CFR 46.102 (f)) [31, 32].

As previously described [33], EAGLE selected all non-European Americans from BioVU as of 2011 for genotyping on the Metabochip (EAGLE BioVU). A total of 11,521 African Americans samples in EAGLE BioVU were genotyped [33]. From among these patients, billing and procedural codes along with text searches were used to identify POAG cases $(n=138)$ and controls $(n=1376)$. In short, controls included patients in BioVU over the age of 60 years whose records did not contain an ICD-9-CM code for any form of glaucoma nor any mention of "glaucoma" in a text search of their 'Problems List.' Manual review of all cases and a subset of controls was performed for quality assurance as previously described [34].

The Metabochip is an Illumina (San Diego, CA) custom array designed for fine-mapping of metabolic and cardiovascular traits. Fine-mapping regions cover 257 loci chosen from SNPs that reached genome-wide significance from select consortium meta-analyses [35]. 
The Metabochip was also designed for replication of GWAS-identified index variants for any phenotype from the GWAS Catalog (http://www.ebi.ac.uk/gwas/) as of 2009. A total of 33 GWAS-index variants representing ocular diseases (including age-related macular degeneration, POAG, normal tension glaucoma, and diabetic retinopathy) as well as related traits (myopia, ocular axial length, HbA1c, cup-to-disc ratio, intraocular pressure, and optic disc size) are directly assayed by the Metabochip (Additional file 1: Table S1).

EAGLE BioVU DNA samples were genotyped using the Metabochip following the manufacturer's protocol (Illumina, Inc.; San Diego, CA.), and 360 HapMap samples, including YRI samples, were genotyped for PAGE-wide cross-study quality control standards [36]. A description of the genotyping protocols and quality control measures has been previously published [30]. In brief, genetic variants were evaluated for deviations from Hardy Weinberg Equilibrium, which may be a result of poor genotyping. Variants with a genotyping call rate $<95 \%$ were removed from further analysis. Principal components (PC) were calculated using EIGENSOFT [37, 38]. At the sample level, DNA samples with poor sample call rate $(<95 \%)$, sex discordance, or evidence of cryptic relatedness were removed from analyses.

\section{Statistical methods}

Individuals included in this analysis were those identified as POAG cases over the age of 20 years and POAG controls over the age of 60 years. An older age threshold was applied in controls to minimize the probability of including potential future cases. African Americans are at increased risk of glaucoma over the age of 40 years, while other populations have an age-associated risk over 60 years. Age was defined as age at diagnosis in cases and age at last clinical exam in controls. T-tests and chi-square tests, where appropriate, were used to compare demographic clinical characteristics between cases and controls in Stata/SE version 14.2.

All common variants (MAF > 0.05) were tested for an association with POAG using logistic regression separately assuming a log-additive genetic model (Additional file 1: Table S2), a recessive model (Additional file 1: Table S3), and a dominant model (Additional file 1: Table S4) adjusted by age, sex, the first three PCs, and median diastolic blood pressure. Analyses were conducted using PLINKv1.90 [39]. Additionally, we tested for an association between POAG and 258 SNPs that passed quality control in the $C D K N 2 B-A S 1$ region of chromosome 14. Pair-wise linkage disequilibrium $\left(\mathrm{r}^{2}\right)$ was calculated in SNAP [40] using YRI 1000 Genomes Project Pilot 1 reference data. Power calculations were performed in Quanto [41] to determine 80\% power to detect an association with a case:control ratio of
1:3, assuming a log-additive model and a genome-wide significance threshold $\left(5 \times 10^{-8}\right)$.

\section{Local ancestry mapping}

Local ancestry for the CDKN2B-AS1 region, located on chromosome 9, was determined for the POAG cases and controls using Local Ancestry in adMixed Populations (LAMP) [42]. Input parameters included the estimated number of generations since admixture (generations $=10$ ), estimated fraction of admixture from each population (African $=0.8$, European $=0.2$ ), and predicted recombination rate $\left(3.4 \times 10^{-7}\right.$ bases $\left.^{-1}\right)$. The number of alleles from the ancestral populations at each SNP that was genotyped in this region was estimated, and the overall fraction of alleles from each ancestral population in this region for each patient was determined. Percent African ancestry was then tested for an association with POAG status using logistic regression using R software version 3.1.3 [43].

\section{Global ancestry mapping}

Global ancestry was calculated using fastSTRUCTURE [44] with all of the Metabochip data. Input parameters were set to default, as recommended by the authors, and the analysis was set to determine the proportion of two populations $(\mathrm{K}=2)$. Admixture plots were graphed using the web graphical interface (http://pophelper.com/) of the R module "pophelper" [45].

\section{Results}

\section{Population characteristics}

A total of 138 African American POAG cases and 1376 controls passed quality control in EAGLE BioVU for the present study. We previously described [34] these cases compared with 4813 controls over the age of 40; in the present study, we compare the same cases with subset of the controls over the age of 60 years (Table 1). Here, cases were younger $(p=0.01)$ with higher cholesterol levels $(183 \mathrm{mg} / \mathrm{dL} ; p=0.01)$, more likely to be female with higher average body mass index $\left(30.1 \mathrm{~kg} / \mathrm{m}^{2}\right)$ in comparison to controls $\left(28.8 \mathrm{~kg} / \mathrm{m}^{2}\right.$ and $169 \mathrm{mg} / \mathrm{dL}$, respectively). Cases also presented with higher triglyceride levels compared to controls $(125 \mathrm{mg} / \mathrm{dL}$ versus $97 \mathrm{mg} / \mathrm{dL} ; p=0.0001)$.

\section{Local ancestry in the CDKN2B-AS1 region}

We previously reported on preliminary tests of association in the CDKN2B-AS1 region [34], which was fine-mapped by the Illumina Metabochip. None of the tests of association were significant after correcting for the 258 common variants tested [34]. As we have already noted, there are multiple explanations for the lack of significant results including limited power, variability in linkage disequilibrium patterns across populations, and genetic heterogeneity. Another possible explanation for the observed null results is that the previous analysis did 
Table 1 Study population characteristics of primary open-angle glaucoma cases and controls among African Americans in EAGLE BioVU

\begin{tabular}{|c|c|c|c|}
\hline Trait & $\begin{array}{l}\text { Cases } \\
(n=138)\end{array}$ & $\begin{array}{l}\text { Controls } \\
(1376)\end{array}$ & $p$-value \\
\hline $\begin{array}{l}\text { Median age at } \\
\text { diagnosis or LCV (years) }\end{array}$ & $62.0(12.0)$ & $67.3(7.8)$ & 0.01 \\
\hline$\%$ female & 63.7 & 56.5 & 0.10 \\
\hline$\%$ hypertensive & 55.1 & 52.5 & 0.50 \\
\hline Median BMI (kg/m²) & $30.1(6.7)$ & $28.8(7.35)$ & 0.44 \\
\hline $\begin{array}{l}\text { Median diastolic blood } \\
\text { pressure }(\mathrm{mm} / \mathrm{Hg})\end{array}$ & $74.5(8.1)$ & $76.0(8.8)$ & 0.97 \\
\hline $\begin{array}{l}\text { Median systolic blood } \\
\text { pressure }(\mathrm{mm} / \mathrm{Hg})\end{array}$ & $134.5(14.1)$ & $135(14.6)$ & 0.88 \\
\hline Median cholesterol (mg/dL) & $183(40.6)$ & $169(46.7)$ & 0.01 \\
\hline Median HDL-C (mg/dL) & $52.5(25.0)$ & $49(17.8)$ & 0.88 \\
\hline Median LDL-C (mg/dL) & $103(42.9)$ & $93(37.4)$ & 0.20 \\
\hline Median triglycerides (mg/dL) & $125(76.3)$ & $97(68.1)$ & 0.0001 \\
\hline
\end{tabular}

Case extraction was described in Restrepo et al. [34]. Control extraction from EAGLE BioVU was also described in Restrepo et al. [34] but restricted to controls $>40$ years of age (as opposed to $>60$ years of age here). Values were defined or calculated for the following: Age at POAG diagnosis was determined by the date of when the POAG billing code (ICD-9-CM 365.11) was first mentioned in the records. Age at last clinic visit (LCV) was taken as the date of the last current procedure terminology (CPT) code mentioned in the records for controls. An individual was classified as hypertensive if he/she met one of three criteria: systolic blood pressure $>140 \mathrm{~mm} / \mathrm{Hg}$, diastolic blood pressure $>90 \mathrm{~mm} / \mathrm{Hg}$, or on hypertension medications all within a 2-year window of when he or she was diagnosed with POAG for cases and a 2-year window of his or her LCV date for controls. Median (and standard deviation) blood pressure (systolic and diastolic), lipids (total cholesterol, high-density lipoprotein cholesterol or HDL-C, low-density lipoprotein cholesterol or LDL-C, and triglycerides), and body mass index (height and weight) were calculated from all labs or measurements available within 2 years of POAG diagnosis or LCV. T-tests and chi-square tests, where appropriate, were used to compare demographic clinical characteristics between cases and controls.

Abbreviations: standard deviation (SD)

not account for local genetic ancestry. We therefore sought to determine whether the total composition of African and European ancestry at this region could account for POAG risk.

Local ancestry for the $C D K N 2 B-A S 1$ region was determined for POAG cases and controls using LAMP [42]. The number of alleles from the ancestral populations at each SNP was estimated, and the overall fraction of alleles from each ancestral population in this region for each patient was calculated. Logistic regression was then performed between POAG case status and percent African ancestry to assess whether ancestry might alter POAG risk. The mean African ancestry for POAG cases and controls at $C D K N 2 B-A S 1$ was 0.90 and 0.58 , respectively (Fig. 1), and the percent of African ancestry in the $C D K N 2 B-A S 1$ region was significantly associated with POAG at $p=2 \times 10^{-6}$. In contrast, the average Metabo-wide global African ancestry for cases and controls was 81.5 and $79.4 \%$, respectively, in agreement with previous estimates $[46,47]$.

\section{Metabochip-wide association of POAG in African Americans}

We tested all SNPs genotyped on the Illumina Metabochip for an association with POAG adjusted for age, sex, the first three principal components, and median diastolic blood pressure (Fig. 2; Additional file 1: Tables S2-S4). No SNP was significantly associated with POAG after adjusting for a strict Bonferroni correction $\left(p<4.04 \times 10^{-7}\right)$. The two most significant associations [chr1:228347779 (rs4846835) and chr1:228354829 (rs34783939)] under the log-additive genetic model are located within the protein coding gene of GALNT2, a member of the glycosyltransferase 2 protein family. GALNT2 was targeted for fine-mapping by the Metabochip based on earlier reported associations with high density lipoprotein cholesterol (HDL-C) and triglyceride levels [48, 49]. It is interesting to note that GALNT2 rs4846835 was associated with dementia and core Alzheimer's disease neuropathologic changes, albeit not at the genome-wide level [50]. Both of these variants also appear as marginally significant under a dominant genetic model (Table 3 [OR $=2.43 \& 2.24$ respectively]. Homozygous carriers for either of the two SNPs are rare in cases and controls at only a frequency of 1 to $2 \%$. Variant rs4846835 heterozygotes account for $9.4 \%$ of cases and $17.5 \%$ of controls, while rs34783939 heterozygotes make up $12.3 \%$ of cases and $23.6 \%$ of controls. The variants are not in strong linkage disequilibrium with one another $\left(r^{2}=0.304\right.$ in YRI, phase 11000 Genomes Project). It is important to note that rs34783939 is most likely multi-allelic based on later versions of the 1000 Genomes Project and other large-scale sequencing efforts.

Additional variants of interest for future studies that were marginally significant in both additive and dominant genetic modes are $\mathrm{rs} 13423742\left(\mathrm{OR}_{\text {additive }}=3.04 ; p=\right.$ $\left.1.14 \times 10^{-4}\right)$, rs9479726 $\left(\mathrm{OR}_{\text {additive }}=0.41 ; p=1.54 \times 10^{-}\right.$ $4)$, and $\mathrm{rs} 1671152\left(\mathrm{OR}_{\text {additive }}=1.91 ; p=1.6 \times 10^{-4}\right)$. Variant rs1671152 is a known missense variant in the glycoprotein VI (GP6) gene. GP6, a collagen receptor, is involved in platelet aggregation [54]. GP6 RNAs are expressed in the retina and brain as shown in the FANTOM5 and GTEx datasets [55, 56]. In 1000 Genomes Project phase $3 \mathrm{CEU}$ the rs1671152 (A) allele has a frequency of 0.182 while the YRI population has a frequency of 0.324, consistent with that observed in EAGLE BioVU African Americans (coded allele frequency $=0.32$ ). The frequency of rs1671152 is twice as high in African Americans compared with European Americans suggesting it could potentially be a population-specific factor.

The intergenic SNP rs9479726 was less frequent in cases compared with controls $\left(\mathrm{OR}_{\text {additive }}=0.41 ; 1.54 \times 10-4\right.$ and $\left.\mathrm{OR}_{\text {dominant }}=0.42 ; 2.5 \times 10^{-4}\right)$. None of the cases were found to be homozygous for the coded allele, while 5.7\% of controls were homozygous. The 'A' allele had a 


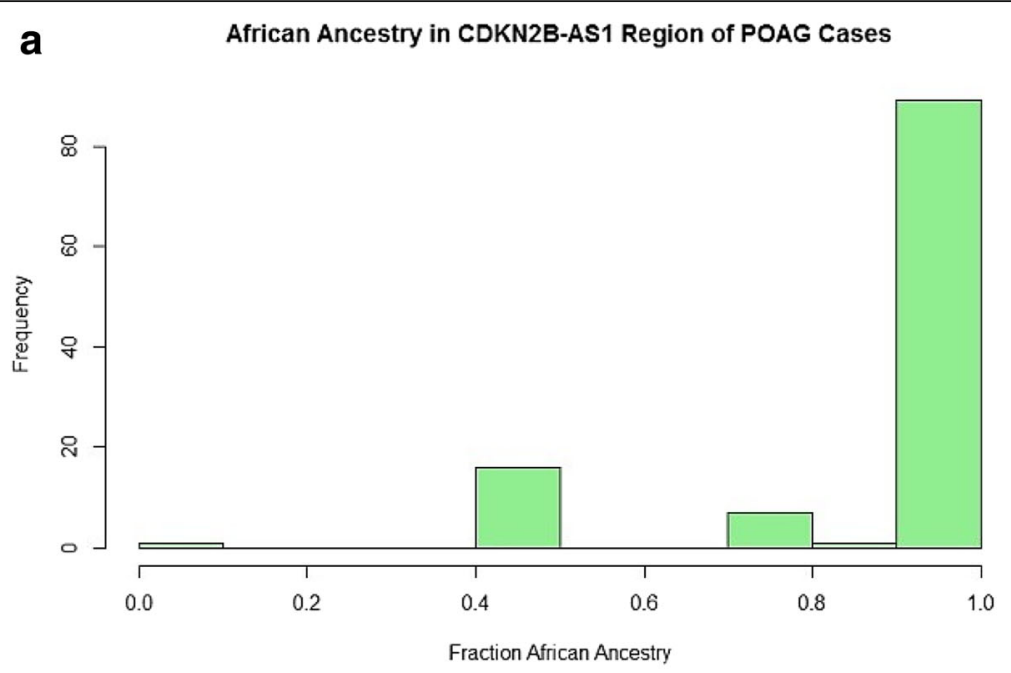

b African Ancestry in CDKN2B-AS1 Region of POAG Controls

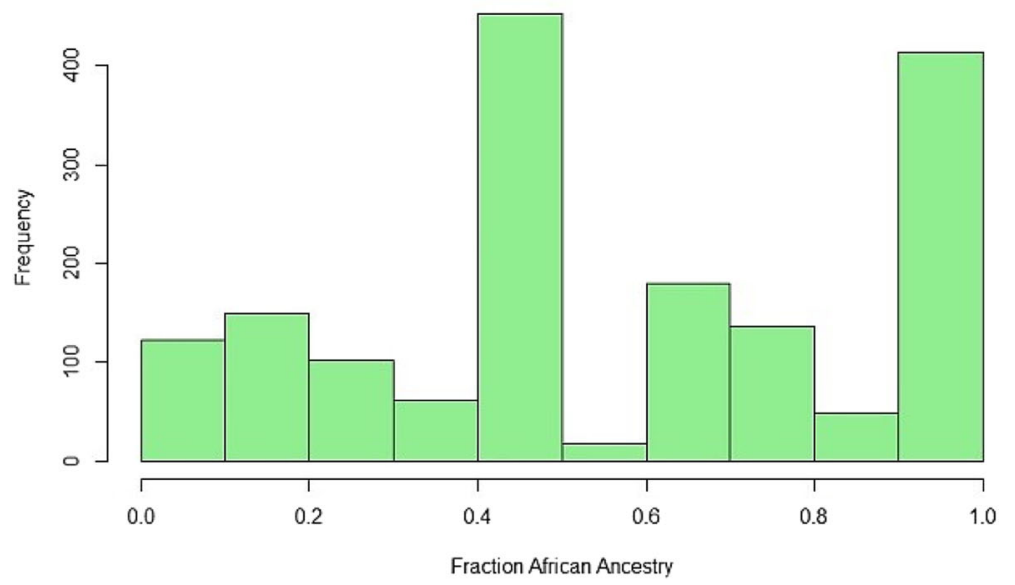

Fig. 1 Distribution of African ancestry at CDKN2B-AS1 in African American primary open-angle glaucoma cases and controls from EAGLE BioVU. Fraction of African ancestry, estimated by LAMP using genotype data available for CDKN2B-AS1 from the lllumina Metabochip, is plotted on the $x$-axis with frequency on the $y$-axis for primary open-angle glaucoma (POAG) a cases $(n=138)$ and $\mathbf{b}$ controls $(n=1376)$. Plots were graphed in $\mathrm{R}$

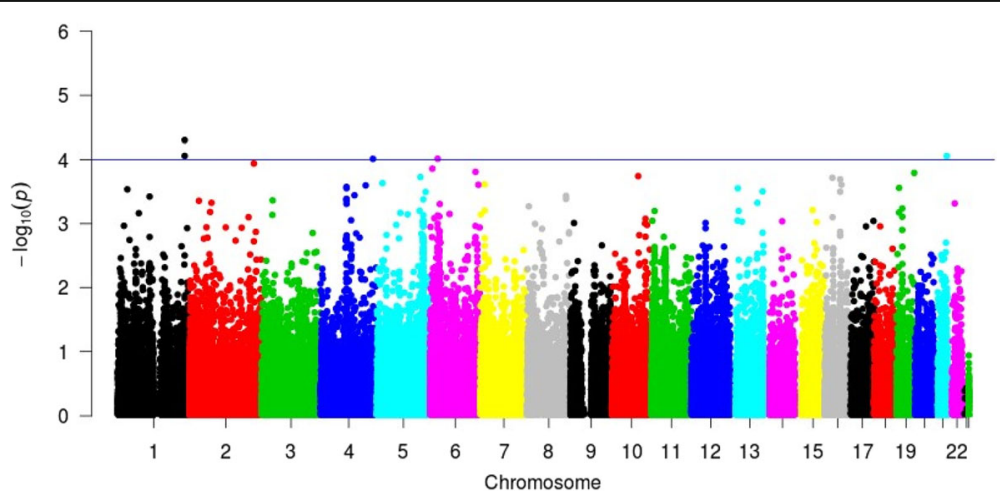

Fig. 2 Manhattan plot of EAGLE BioVU primary open-angle glaucoma Metabochip-wide tests of association in African Americans. Logistic regression assuming an additive genetic model was performed for 138 cases and 1376 controls adjusted by age, sex, principal components, and median diastolic blood pressure. $P$-values $\left[\left(-\log _{10}\right)\right.$ on the $y$-axis] for each test of association are plotted by chromosome (x-axis). The blue line depicts a suggestive significance threshold of $p<5.0 \times 10^{-4}$ 
Table 2 Ten most significant results for primary open-angle glaucoma Metabochip-wide genetic associations in African Americans

\begin{tabular}{llllllll}
\hline CHR & SNP & Gene & CA & CAF & OR & $95 \%$ Cl & $p$-value \\
\hline 1 & rs4846835 & GALNT2 & A & 0.11 & 2.37 & $1.56-3.60$ & $5.00 \times 10^{-5}$ \\
1 & rs34783939 & GALNT2 & C & 0.15 & 2.09 & $1.44-3.02$ & $8.73 \times 10^{-5}$ \\
21 & rs9982695 & C210rf33 & A & 0.24 & 2.09 & $1.44-3.02$ & $8.74 \times 10^{-5}$ \\
4 & rs3775202 & VEGFC & G & 0.43 & 1.92 & $1.38-2.66$ & $9.70 \times 10^{-5}$ \\
2 & rs13423742 & FN1 & C & 0.06 & 3.04 & $1.73-5.36$ & $1.14 \times 10^{-4}$ \\
6 & rs7454156 & BMP6 & G & 0.18 & 2.08 & $1.42-3.02$ & $1.37 \times 10^{-4}$ \\
6 & rs9479726 & RGS17-OPRM1 & A & 0.24 & 0.41 & $0.25-0.64$ & $1.54 \times 10^{-4}$ \\
19 & rs1671152 & GP6 & A & 0.32 & 1.91 & $1.36-2.68$ & $1.60 \times 10^{-4}$ \\
10 & rs286489 & LOC101929727 & A & 0.28 & 1.90 & $1.35-2.66$ & $1.80 \times 10^{-4}$ \\
5 & rs4336354 & HTR4 & G & 0.09 & 2.51 & $1.54-4.07$ & $1.86 \times 10^{-4}$ \\
\hline
\end{tabular}

Logistic regression assuming an additive genetic model was performed for 138 cases and 1376 controls adjusted by age, sex, principal components, and median diastolic blood pressure. For the ten most significant associations, chromosome (CHR), SNP ID (rs number), gene, coded allele (CA), coded allele frequency (CAF), odds ratio (OR), $95 \%$ confidence interval $(\mathrm{Cl})$, and $p$-value are given

frequency of $24 \%$ in the overall population, with $10.8 \%$ of cases and $37.6 \%$ of controls being heterozygous carriers.

One SNP (i.e., rs7454156) was consistently associated with POAG at $p<5.0 \times 10^{-4}$ in both the additive (Table 2) and recessive genetic models (Table 3 ). This intronic variant (G) in the bone morphogenetic protein 6 (BMP6) was found to be homozygous in $5 \%$ of controls and $2.5 \%$ of cases. In a mouse model of hemochromatosis, mutations in a BMP6 co-receptor (i.e., $H J V$ ) were found to result in an accumulation of iron in mouse retinal tissues and upregulation of $B M P 6$ along with upregulation of VEGF that resulted in subsequent abnormal vascularization of the retina [57].

While certain variants were found to be associated with POAG in both dominant/additive and recessive/ additive models, we found that no SNPs were consistently associated with POAG in both dominant and recessive models.

\section{Discussion}

Epidemiologic and clinical studies have demonstrated that POAG risk is higher in African-descent populations compared with other populations such as European Americans. To identify genetic variants associated with POAG risk that are specific to African-descent populations or shared across world populations, we identified African American POAG cases and controls in a clinic setting using electronic health records to conduct genetic associations studies in the fine-mapped region of CDKN2B-AS1 and Metabochip-wide [34]. Overall, we found evidence that the percentage of African ancestry at $C D K N 2 B-A S 1$ was strongly correlated with POAG case status $\left(p=2 \times 10^{-6}\right)$. POAG cases on average contained $90 \%$ African ancestral alleles at the $C D K N 2 B-A S 1$ region versus controls which were only $58 \%$ African, suggesting that African-specific variation may indeed being driving risk at this locus. Additionally, the lack of strong statistical associations with individual SNPs but an association with gene-based African ancestry suggests that gene $\mathrm{x}$ gene or gene $\mathrm{x}$ environment interactions may be involved but which will require larger sample sizes to accurately assess the possibility.

Common variants in CDKN2B-ASI are consistently associated with POAG in European-descent populations $[25,27,51]$. We [34] and others [27, 52, 53] have demonstrated that these same variants are inconsistently associated with POAG in African-descent populations. The lack of association in African-descent populations is likely due to limited power, a consequence of smaller

Table 3 Primary open-angle glaucoma Metabochip-wide genetic associations in African Americans for dominant and recessive models that overlap with the most significant results for the additive genetic model

\begin{tabular}{llllllll}
\hline CHR & SNP & Gene & CA & OR & $95 \%$ Cl & $p$-value & Genetic model \\
\hline 1 & rs4846835 & GALNT2 & A & 2.43 & $1.56-3.74$ & $6.59 \times 10^{-5}$ & dominant \\
1 & rs34783939 & GALNT2 & C & 2.24 & $1.47-3.39$ & $1.6 \times 10^{-4}$ & dominant \\
2 & rs13423742 & FN1 & C & 2.82 & $1.63-4.86$ & $2.02 \times 10^{-4}$ & dominant \\
6 & rs9479726 & RGS17-OPRM1 & A & 0.42 & $0.26-0.67$ & $2.5 \times 10^{-4}$ & dominant \\
19 & rs1671152 & GP6 & A & 2.24 & $1.42-3.53$ & $5.2 \times 10^{-4}$ & dominant \\
6 & rs7454156 & BMP6 & G & 5.14 & $2.54-10.37$ & $4.87 \times 10^{-6}$ & recessive \\
\hline
\end{tabular}

Logistic regression assuming a dominant genetic model adjusted by age, sex, principal components, and median diastolic blood pressure. Chromosome (CHR), SNP ID (rs number), gene, coded allele (CA), odds ratio (OR), $95 \%$ confidence interval $(\mathrm{Cl}), p$-value, and assumed genetic model are given 
sample sizes and considerably lower allele frequencies compared with studies of European-descent populations. For example, CDKN2B-AS1 rs2157719 has a minor allele frequency of 3 and $46 \%$ in African Americans (ASW) and Europeans (CEU), respectively, in phase 3 of the 1000 Genomes Project. Originally discovered in a European POAG cohort [25], rs2157719 was found to be associated with optic nerve degeneration in glaucoma patients with an odds ratio of 1.45 . The present study is powered $(80 \%)$ to detect associations for common variants ( $\geq 15 \%$ MAF) with large effect sizes (at least 2.9 odds ratio) at genome-wide significance $\left(5 \times 10^{-8}\right)$. The small sample size of this study is underpowered to detect associations for less frequent variants and/or variants with smaller effect sizes. Although we could not generalize these associations in this study sample, we note that this locus is still important in POAG risk as evidenced by the association between African ancestry at this locus and POAG. It is also interesting to note that the CDKN2B-AS1 rs2157719 allele associated with lower odds of POAG $(\mathrm{C} / \mathrm{G})$ is the ancestral allele yet the minor allele in all 1000 Genomes Project populations. The high frequency of the derived allele at rs2157719 may be due to chance, positive selection (and possible antagonistic pleiotropy), or an error in ancestral allele assignment, among other possibilities.

\section{Conclusions}

Here, we show a significant association between POAG risk and local African genetic ancestry at CDKN2B-AS1 $\left(p=2 \times 10^{-6}\right)$. While not identifying significant single SNP-POAG associations after adjusting for multiple testing, the results still suggest that $C D K N 2 B-A S 1$ is an important locus of POAG risk among African Americans, warranting further investigation to identify genetic variants or epigenetic regulators that may be acting in conjunction with this locus. When gauging the strengths and limitations of this study, perhaps its greatest strength is the expansion of knowledge in African Americans, a population far too often underrepresented in biomedical research [58]. Additional strengths involve the utilization of electronic health records as a cost efficient and data-dense resource for studies. A major limitation of our study is statistical power. Nevertheless, this study is one of only a handful to assess the genetic architecture of POAG in African Americans.

\section{Additional file}

Additional file 1: Table S1. Genome-wide association study (GWAS)identified index variants associated with ocular disease and related traits directly assayed by the Illumina Metabochip. Table S2. The 100 most significant results for the genetic association analysis of the

Metabochip and African American primary open-angle glaucoma cases $(n=138)$ and controls $(n=1376)$. Table S3. Results $(p<0.0001)$ for RECESSIVE genetic models for Metabochip-wide tests of association in African American primary open-angle glaucoma cases $(n=138)$ and controls $(n=1376)$. Table S4. Results $(p<0.0001)$ for DOMINANT genetic models for Metabochip-wide tests of association in African American primary open-angle glaucoma cases $(n=138)$ and controls $(n=$ 1376). (DOCX $52 \mathrm{~kb}$ )

\section{Abbreviations}

EAGLE: Epidemiologic Architecture for Genes Linked to Environment; GWAS: Genome-wide association studies; HDL-C: High density lipoprotein cholesterol; IRB: Vanderbilt Institutional Review Board; LAMP: Local Ancestry in admixed Populations; MAF: Minor allele frequency; OR: Odds ratio; PAGE: Population Architecture using Genomics and Epidemiology; PC: Principal components; POAG: Primary open-angle glaucoma; VUMC: Vanderbilt University Medical Center

\section{Funding}

This work was supported by National Institutes of Health U01 HG004798 and its ARRA supplements. The cost of publication was funded by Case Western Reserve University' Institute for Computational Biology. NAR was supported by the National Institutes of Health (NIH) Quantitative Ocular Genomics Training Program Pre-doctoral Trainee (1T32EY021453). The dataset (s) used for the analyses described were obtained from Vanderbilt University Medical Center's BioVU which is supported by institutional funding and the National Center for Research Resources, Grant UL1 RR024975-01 (now at the National Center for Advancing Translational Sciences, Grant 2 UL1 TR000445-06).

\section{Availability of data and materials}

Data are available in the database of Genotypes and Phenotypes (dbGaP) study accession phs000297.v1.p1.

\section{About this supplement}

This article has been published as part of BMC Medical Genomics Volume 11 Supplement 3, 2018: Selected articles from the 7th Translational Bioinformatics Conference (TBC 2017): medical genomics. The full contents of the supplement are available online at https://bmcmedgenomics.biomedcentral.com/articles/ supplements/volume-11-supplement-3.

\section{Authors' contributions}

DCC and NAR designed the study. NAR and EFE collected and prepared the data, and NAR and SL analyzed the data. NAR drafted the manuscript. DCC, $\mathrm{SL}$, and EFE were major contributors in revising the manuscript critically for all important intellectual content. All authors gave approval to the final version of the manuscript and agreed to be accountable to all aspects of the work.

\section{Ethics approval and consent to participate}

The data in this study were de-identified in accordance with provisions of Title 45, Code of Federal Regulations, part 46 (45 CFR 46); therefore, this study was considered non-human subjects research by the Vanderbilt University Internal Review Board.

\section{Consent for publication}

Not applicable.

\section{Competing interests}

The authors declare that they have no competing interests.

\section{Publisher's Note}

Springer Nature remains neutral with regard to jurisdictional claims in published maps and institutional affiliations.

\section{Author details}

${ }^{1}$ Department of Population and Quantitative Health Sciences, Institute for Computational Biology, Case Western Reserve University, 2103 Cornell Road, Wolstein Research Building, Suite 2-527, Cleveland, OH 44106, USA. ²Eastern Virginia Medical School, Norfolk, VA, USA. ${ }^{3}$ Vanderbilt Institute for Clinical and Translational Research, Vanderbilt University Medical Center, Nashville, TN, USA. 


\section{Published: 14 September 2018}

\section{References}

1. The Eye Diseases Prevalence Research Group. Causes and prevalence of visual impairment among adults in the United States. Arch Ophthalmol. 2004;122(4):477-85. https://doi.org/10.1001/archopht.122.4.477.

2. Stein JD, Kim DS, Niziol LM, Talwar N, Nan B, Musch DC, et al. Differences in rates of glaucoma among Asian Americans and other racial groups, and among various asian ethnic groups. Ophthalmology. 2011;118(6):1031-7. https://doi.org/10.1016/j.ophtha.2010.10.024. PMC3109193

3. Friedman DS, Wolfs RC, O'Colmain BJ, Klein BE, Taylor HR, West S, et al. Prevalence of open-angle glaucoma among adults in the United States. Arch Ophthalmol. 2004;122(4):532-8. https://doi.org/10.1001/archopht. 122.4.532. PMC2798086

4. Quigley HA, Broman AT. The number of people with glaucoma worldwide in 2010 and 2020. Br J Ophthalmol. 2006;90(3):262-7. https://doi.org/10. 1136/bjo.2005.081224. PMC1856963

5. Ladapo JA, Kymes SM, Ladapo JA, Nwosu VC, Pasquale LR. Projected clinical outcomes of glaucoma screening in African American individuals. Arch Ophthalmol. 2012;130(3):365-72. https://doi.org/10.1001/archopthalmol.2011.1224.

6. Leske M, Connell AS, Wu S, Hyman LG, Schachat AP. Risk factors for openangle glaucoma: the Barbados eye study. Arch Ophthalmol. 1995;113(7): 918-24. https://doi.org/10.1001/archopht.1995.01100070092031.

7. Pan C-W, Cheung CY, Aung T, Cheung C-M, Zheng Y-F, Wu R-Y, et al. Differential associations of myopia with major age-related eye diseases: the Singapore Indian eye study. Ophthalmology. 2013;120(2):284-91. https://doi. org/10.1016/j.ophtha.2012.07.065.

8. Chandrasekaran S, Cumming RG, Rochtchina E, Mitchell P. Associations between elevated intraocular pressure and Glaucoma, use of Glaucoma medications, and 5-year incident cataract: the Blue Mountains eye study. Ophthalmology. 2006; 113(3):417-24. https://doi.org/10.1016/j.ophtha.2005.10.050.

9. Jiang $X$, Varma $R$, Wu S, Torres M, Azen SP, Francis BA, et al. Baseline risk factors that predict the development of open-angle Glaucoma in a population: the Los Angeles Latino eye study. Ophthalmology. 2012;119(11): 2245-53. https://doi.org/10.1016/j.ophtha.2012.05.030. PMC3474872

10. Budde WM. Heredity in primary open-angle glaucoma. Curr Opin Ophthalmol. 2000;11(2):101-6.

11. Tielsch JM, Katz J, Sommer A, Quigley HA, Javitt JC. Family history and risk of primary open angle glaucoma: the Baltimore eye survey. Arch Ophthalmol. 1994;112(1):69-73. https://doi.org/10.1001/archopht.1994. 01090130079022.

12. Freeman EE, Roy-Gagnon M-H, Descovich D, Massé H, Lesk MR. The heritability of glaucoma-related traits corneal hysteresis, central corneal thickness, intraocular pressure, and choroidal blood flow pulsatility. PLoS One. 2013;8(1): e55573. https://doi.org/10.1371/journal.pone.0055573. PMC3559508

13. van Koolwijk LME, Despriet DDG, van Duijn CM, Pardo Cortes LM, Vingerling $J R$, Aulchenko YS, et al. Genetic contributions to Glaucoma: heritability of intraocular pressure, retinal nerve Fiber layer thickness, and optic disc morphology. Invest Ophthalmol Vis Sci. 2007;48(8):3669-76. https://doi.org/ 10.1167/iovs.06-1519.

14. Charlesworth J, Kramer PL, Dyer T, Diego V, Samples JR, Craig JE, et al. The path to open-angle glaucoma gene discovery: endophenotypic status of intraocular pressure, cup-to-disc ratio, and central corneal thickness. Invest Ophthalmol Vis Sci. 2010;51(7):3509-14. https://doi.org/10.1167/iovs.09-4786. PMC2904007

15. Chang TC, Congdon NG, Wojciechowski R, Muñoz B, Gilbert D, Chen P, et al. Determinants and heritability of intraocular pressure and cup-to-disc ratio in a defined older population. Ophthalmology. 2005;112(7):1186-91. https:// doi.org/10.1016/j.ophtha.2005.03.006. PMC3124001

16. Findl O, Rainer G, Dallinger S, Dorner G, Polak K, Kiss B, et al. Assessment of optic disk blood flow in patients with open-angle glaucoma. Am J Ophthalmol. 2000;130(5):589-96. https://doi.org/10. 1016/S0002-9394(00)00636-X.

17. Fontana L, Poinoosawmy D, Bunce CV, O'Brien C, Hitchings RA. Pulsatile ocular blood flow investigation in asymmetric normal tension glaucoma and normal subjects. Br J Ophthalmol. 1998;82(7):731-6. https://doi.org/10. 1136/bjo.82.7.731. PMC1722652

18. Stone EM, Fingert JH, Alward WLM, Nguyen TD, Polansky JR, Sunden SLF, et al. Identification of a gene that causes primary open angle Glaucoma. Science. 1997;275(5300):668-70. https://doi.org/10.1126/science.275.5300.668.
19. Rezaie T, Child A, Hitchings R, Brice G, Miller L, Coca-Prados M, et al. Adultonset primary open-angle Glaucoma caused by mutations in Optineurin. Science. 2002;295(5557):1077-9. https://doi.org/10.1126/science.1066901.

20. Monemi S, Spaeth G, DaSilva A, Popinchalk S, litchev E, Liebmann J, et al. Identification of a novel adult-onset primary open-angle glaucoma (POAG) gene on 5q22.1. Hum Mol Genet. 2005;14(6):725-33. https://doi.org/10. 1093/hmg/ddi068.

21. Adam MF, Belmouden A, Binisti P, Brézin AP, Valtot F, Béchetoille A, et al. Recurrent mutations in a single exon encoding the evolutionarily conserved Olfactomedin-homology domain of TIGR in familial open-angle Glaucoma. Hum Mol Genet. 1997;6(12):2091-7. https://doi.org/10.1093/hmg/6.12.2091.

22. Suzuki Y, Shirato S, Taniguchi F, Ohara K, Nishimaki K, Ohta S. Mutations in the TIGR gene in familial primary open-angle Glaucoma in Japan. Am J Hum Genet. 1997;61(5):1202-4. https://doi.org/10.1086/301612. PMC1716051

23. Nakano M, Ikeda Y, Tokuda Y, Fuwa M, Omi N, Ueno M, et al. Common variants in CDKN2B-AS1 associated with optic-nerve vulnerability of glaucoma identified by genome-wide association studies in Japanese. PLoS One. 2012; 7(3):e33389. https://doi.org/10.1371/journal.pone.0033389. PMC3299784

24. Osman W, Low SK, Takahashi A, Kubo M, Nakamura Y. A genome-wide association study in the Japanese population confirms 9p21 and 14q23 as susceptibility loci for primary open angle glaucoma. Hum Mol Genet. 2012; 21(12):2836-42. https://doi.org/10.1093/hmg/dds103.

25. Wiggs JL, Yaspan BL, Hauser MA, Kang JH, Allingham RR, Olson LM, et al. Common variants at 9p21 and 8q22 are associated with increased susceptibility to optic nerve degeneration in Glaucoma. PLoS Genet. 2012; 8(4):e1002654. https://doi.org/10.1371/journal.pgen.1002654. PMC3342074

26. Thorleifsson G, Walters GB, Hewitt AW, Masson G, Helgason A, DeWan A, et al. Common variants near CAV1 and CAV2 are associated with primary open-angle glaucoma. Nat Genet. 2010;42(10):906-9. https://doi.org/10. 1038/ng.661. PMC3222888

27. Li Z, Allingham RR, Nakano M, Jia L, Chen Y, Ikeda Y, et al. A common variant near TGFBR3 is associated with primary open angle glaucoma. Hum Mol Genet. 2015;24(13):3880-92. https://doi.org/10.1093/hmg/ddv128. PMC4459396

28. Liu W, Liu Y, Challa P, Herndon LW, Wiggs JL, Girkin CA, et al. Low prevalence of myocilin mutatons in an African American population wiht primary open-angle glaucoma. Mol Vision. 2012;18:2241-6. PMC3429360

29. Matise TC, Ambite JL, Buyske S, Carlson CS, Cole SA, Crawford DC, et al. The next PAGE in understanding complex traits: design for the analysis of population architecture using genetics and epidemiology (PAGE) study. Am J Epidemiol. 2011;174(7):849-59. https://doi.org/10.1093/aje/kwr160. PMC3176830

30. Buyske S, Wu Y, Carty CL, Cheng I, Assimes TL, Dumitrescu L, et al. Evaluation of the Metabochip genotyping Array in African Americans and implications for fine mapping of GWAS-identified Loci: the PAGE study. PLoS One. 2012;7(4): e35651. https://doi.org/10.1371/journal.pone.0035651. PMC3335090

31. Roden DM, Pulley JM, Basford MA, Bernard GR, Clayton EW, Balser JR, et al. Development of a large-scale De-identified DNA biobank to enable personalized medicine. Clin Pharmacol Ther. 2008;84(3):362-9. https://doi. org/10.1038/clpt.2008.89. PMC3763939

32. Pulley J, Clayton E, Bernard GR, Roden DM, Masys DR. Principles of Human Subjects Protections Applied in an Opt-Out, De-identified Biobank. Clin Transl Sci. 2010;3(1):42-8. https://doi.org/10.1111/j.1752-8062.2010.00175.x. PMC3075971

33. Crawford DC, Goodloe R, Farber-Eger E, Boston J, Pendergrass SA, Haines LL, et al. Leveraging epidemiologic and clinical collections for genomic studies of complex traits. Hum Hered. 2015;79(3-4):137-46. https://doi.org/10.1159/ 000381805. PMC4528966

34. Restrepo NA, Farber-Eger E, Goodloe R, Haines JL, Crawford DC. Extracting primary open-angle glaucoma from electronic medical records for genetic association studies. PLoS One. 2015;10(6):e0127817. https://doi.org/10.1371/ journal.pone.0127817. PMC4465698

35. Voight BF, Kang HM, Ding J, Palmer CD, Sidore C, Chines PS, et al. The Metabochip, a custom genotyping array for genetic studies of metabolic, cardiovascular, and anthropometric traits. PLOS Genet. 2012;8(8):e1002793. https://doi.org/10.1371/journal.pgen.1002793. PMC3410907

36. Crawford DC, Goodloe R, Brown-Gentry K, Wilson S, Robberson J, Gillani NB, et al. Characterization of the Metabochip in diverse populations from the International HapMap Project in the Epidemiologic Architecture for Genes Linked to Environment (EAGLE) Project. Pac Symp Biocomput. 2013;18:18899. PMC3584704 
37. Price AL, Patterson NJ, Plenge RM, Weinblatt ME, Shadick NA, Reich D. Principal components analysis corrects for stratification in genome-wide association studies. Nat Genet. 2006;38(8):904-9.

38. Patterson N, Price AL, Reich D. Population structure and Eigenanalysis. PLoS Genet. 2006;2(12):e190. https://doi.org/10.1371/journal.pgen.0020190.

39. Purcell S, Neale B, Todd-Brown K, Thomas L, Ferreira MA, Bender D, et al. PLINK: a tool set for whole-genome association and population-based linkage analysis. Am J Hum Genet. 2007;81(3):559-75.

40. Johnson AD, Handsaker RE, Pulit S, Nizzari MM, ODonnell CJ, de Bakker PI. SNAP: a web-based tool for identification and annotation of proxy SNPS using HapMap. Bioinformatics. 2008;24(24):2938-9. https://doi.org/10.1093/ bioinformatics/btn564. PMC2720775

41. Gauderman WJ. Sample size requirements for association studies of genegene interaction. Am J Epidemiol. 2002;155(5):478-84.

42. Baran Y, Pasaniuc B, Sankararaman S, Torgerson DG, Gignoux C, Eng $C$, et al. Fast and accurate inference of local ancestry in Latino populations. Bioinformatics. 2012;28(10):1359-67. https://doi.org/10. 1093/bioinformatics/bts144. PMC3348558

43. R: A language and environment for statistical computing. Vienna, Austria: $R$ Foundation for Statistical Computing; 2013.

44. Raj A, Stephens M, Pritchard JK. fastSTRUCTURE: Variational inference of population structure in large SNP data sets. Genetics. 2014;197(2):573-89. https://doi.org/10.1534/genetics.114.164350. PMC4063916

45. Francis RM. pophelper: an R package and web app to analyse and visualize population structure. Mol Ecol Resour. 2017;17(1):27-32. https://doi.org/10. 1111/1755-0998.12509.

46. Parra EJ, Marcini A, Akey J, Martinson J, Batzer MA, Cooper R, et al. Estimating African American admixture proportions by use of population-specific alleles. Am J Hum Genet. 1998;63(6):1839-51. https://doi.org/10.1086/302148. PMC1377655

47. Baharian S, Barakatt M, Gignoux CR, Shringarpure S, Errington J, Blot WJ, et al. The great migration and African-American genomic diversity. PLoS Genet. 2016;12(5):e1006059. https://doi.org/10.1371/journal.pgen.1006059. PMC4883799

48. Willer CJ, Sanna S, Jackson AU, Scuteri A, Bonnycastle LL, Clarke R, et al. Newly identified loci that influence lipid concentrations and risk of coronary artery disease. Nat Genet. 2008:40(2):161-9. https://doi.org/10.1038/ng.76. PMC5206900

49. Kathiresan S, Melander O, Guiducci C, Surti A, Burtt NP, Rieder MJ, et al. Six new loci associated with blood low-density lipoprotein cholesterol, highdensity lipoprotein cholesterol or triglycerides in humans. Nat Genet. 2008; 40(2):189-97. https://doi.org/10.1038/ng.75. PMC2682493

50. Beecham GW, Hamilton K, Naj AC, Martin ER, Huentelman M, Myers AJ, et al. Genome-wide association meta-analysis of neuropathologic features of Alzheimer's disease and related dementias. PLoS Genet. 2014;10(9): e1004606. https://doi.org/10.1371/journal.pgen.1004606. PMC4154667

51. Pasquale LR, Loomis SJ, Kang JH, Yaspan BL, Abdrabou W, Budenz DL, et al. CDKN2B-AS1 genotype-glaucoma feature correlations in primary openangle glaucoma patients from the United States. Am J Ophthalmol. 2013; 155(2):342-53.e5. https://doi.org/10.1016/j.ajo.2012.07.023. PMC3544983

52. Williams SE, Carmichael TR, Allingham RR, Hauser M, Ramsay M. The genetics of POAG in black South Africans: a candidate gene association study. Sci Rep. 2015;5:8378. https://doi.org/10.1038/srep08378. PMC4323640

53. Cao D, Jiao X, Liu X, Hennis A, Leske MC, Nemesure B, et al. CDKN2B polymorphism is associated with primary open-angle glaucoma (POAG) in the Afro-Caribbean population of Barbados, West Indies. PLoS One. 2012; 7(6):e39278. https://doi.org/10.1371/journal.pone.0039278. PMC3384655

54. Jandrot-Perrus M, Busfield S, Lagrue A-H, Xiong X, Debili N, Chickering T, et al. Cloning, characterization, and functional studies of human and mouse glycoprotein VI: a platelet-specific collagen receptor from the immunoglobulin superfamily. Blood. 2000;96(5):1798-807.

55. Lonsdale J, Thomas J, Salvatore M, Phillips R, Lo E, Shad S, et al. The Genotype-Tissue Expression (GTEx) project. Nat Genet. 2013;45(6):580-85.

56. Yu NY-L, Hallström BM, Fagerberg L, Ponten F, Kawaji H, Carninci P, Forrest ARR. The FANTOM Consortium, Yoshihide Hayashizaki, Mathias Uhlén, Carsten O. Daub. Complementing tissue characterization by integrating transcriptome profiling from the Human Protein Atlas and from the FANTOM5 consortium. Nucleic Acids Res. 2015;43(14):6787-98.
57. Arjunan P, Gnanaprakasam JP, Ananth S, Romej MA, Rajalakshmi V-K, Prasad PD, Martin PM, Gurusamy M, Thangaraju M, Bhutia YD, Ganapathy V. Increased Retinal Expression of the Pro-Angiogenic Receptor GPR91 via BMP6 in a Mouse Model of Juvenile Hemochromatosis. Investigative Opthalmology \& Visual Science. 2016;57(4):1612.

58. Popejoy AB, Fullerton SM. Genomics is failing on diversity. Nature 2016; 538(7624):161-164

\section{Ready to submit your research? Choose BMC and benefit from:}

- fast, convenient online submission

- thorough peer review by experienced researchers in your field

- rapid publication on acceptance

- support for research data, including large and complex data types

- gold Open Access which fosters wider collaboration and increased citations

- maximum visibility for your research: over $100 \mathrm{M}$ website views per year

At BMC, research is always in progress.

Learn more biomedcentral.com/submissions 